\title{
Variation in fatty acid content and composition among Iranian fennel landraces
}

\author{
Keivan Bahmani ${ }^{1}$, Ali Izady- Darbandi ${ }^{2}$, Azam Akbari $^{3}$, and Ryan Warner ${ }^{1}$ \\ ${ }^{1}$ Michigan State University of Agriculture and Applied Science \\ ${ }^{2}$ Tehran University \\ ${ }^{3}$ Affiliation not available
}

February 26, 2021

\begin{abstract}
One of the factors determining drug quality in bitter fennel is the types and quantities of fatty acids stored in the seeds. We measured the fatty acid content of 50 Iranian fennel landraces. Fatty acid concentration of the 50 fennel landraces ranged from 9.5 to $23 \%$ of seed mass, and the highest amounts of fatty acid content among the early maturing races belonged to Hamedan and Arak (19.5 and 18.5\%, respectively), among the medium maturing races to Marvdasht, Kohn and Meshkin Shahr (23, 20.5 and $19 \%$, respectively), and among the late-maturing races to Sari $(21 \%)$. The highest fatty acid yields belonged to Fasa (65.3 $\mathrm{ml} / \mathrm{m} 2)$ among the early maturing races, Meshkin Shahr and Moqhan (92.5 and $85.4 \mathrm{ml} / \mathrm{m} 2)$ among the medium maturing races, and Sari $(71.4 \mathrm{ml} / \mathrm{m} 2)$ among the late-maturing races. The main compositions of fatty acids, measured in twelve of the landraces, were oleic acid (52-64\%), linoleic acid (26-39\%), palmitic acid (0.3-4.1\%), stearic acid (1.3-2.4\%), linolenic acid (0.6-3.6\%) and myristic acid (0.35-1.07\%). It was observed that landraces with high oleic acid content originated from regions with a dry and warm climate, while landraces with high linoleic acid content originated from regions with a humid and cool climate. Understanding relationships between the fatty acid profile and landrace origin climate may improve the efficiency of identifying landraces with specific fennel chemotypes. In conclusion, these results indicate that some of these fennel landraces have the potential to be complementary sources of certain fatty acids, such as oleic and linoleic acids.
\end{abstract}

\section{Introduction}

The oldest evidence of medicinal plant usage goes back to 60,000 years ago to Kurdistan in Shanidar cave (Lietava, 1992). Bitter fennel is one of the oldest medicinal plants that due to possessing certain metabolites, is used as flavoring agents in food and beverages, and as curative agents in pharmaceutical products (Hornok, 1992).

Bitter fennel (Foeniculum vulgare var. Vulgare), hereafter just fennel, as the source subspecies for fennelderived drugs, originated from Mediterranean regions, but now has been naturalized in many other regions (Hornok, 1992). Fennel produces several valuable phytochemicals in the seeds. One group of these compounds is fatty acids, also called fixed oils, or just oil (Hornok, 1992).

Plant-based oils are considered heathier than animal-based oils due to a lower ratio of omega- 6 to omega-3 fatty acids, and a higher ratio of monounsaturated to polyunsaturated and saturated fatty acids (Vidrih, et al., 2009). Exploring new crops as complementary or substituting sources of fatty acids to the current main oil crops, including soybeans, sunflower, canola (FAO, 2018), is valuable for meeting market demand, and diversifying our oil production sources. Currently, species within the family Apiaceae are gaining a lot of attention as potential sources of fatty acids. Among Apiaceae species, fennel is a candidate as a new source of fatty acids, due to its suitability for mechanized mass production, high seed yield potential (400-3000 
$\mathrm{kg} / \mathrm{ha}$ ), and high fatty acid content (12-20\% of seed mass) (Matthaus and Ozcan, 2015; He and Huang, 2011; Cosge et al., 2008; Gupta et al., 1995; Reiter, et al., 1998).

Seeds are the main storage location of fatty acids in fennel, and they can contain from 3 to $20 \%$ oil with the major fatty acids being C18:1 isomers (25-83\%), C18:2 or linoleic acid (1-17\%), C16:0, or palmitic acid (0-13\%), C14:0 or myristic acid (0-6.5\%), C18:3(N3) or linolenic acid (0.3-4\%), C18:0 or stearic (0.8-1.9\%), and C20:0 or arachidic acid (0-0.4\%) (Rezaei Chiyaneh et al., 2020; Hayat et al., 2019; Sayed Ahmad et al., 2018; Agarwal et al., 2018; Rebey et al., 2016; Nguyen et al., 2015; Acimovic et al., 2015; Bogdanov et al., 2015; Barros et al., 2010; Vidrih, et al., 2009; Cosge et al., 2008; Singh et al., 2006; Gupta et al., 1995; Reiter et al., 1998). Petroselinic acid (18:1-cis6), oleic acid (18:1-9cis), and vaccenic acid (18:1-11cis) are three positional isomers of $\mathrm{C} 18: 1$, which can make separation and quantification cumbersome, but petroselinic acid is the major isomer (Reiter et al., 1998). Both oleic acid and linoleic acid are essential fatty acids with many health benefits in human nutrition, and numerous usages in various industries (Sales Campos et al., 2013; Simopoulos, 2008). The high concentration of oleic acid (77-83\% of seed mass) in an Iranian fennel genotype in different intercropping systems was reported by Rezaei Chiyaneh et al. (2020).

According to our previous studies on Iranian fennel landraces, there is significant genetic diversity (Bahmani et al., 2012 and 2013) and agro-morphological variation among fennel landraces for maturity habit, seed yield, and essential oil yield composition (Bahmani et al, 2015 and 2016). In terms of maturity habit, Iranian fennel landraces are divided into early, medium, and late maturity landraces (120, 180, and 230 days to harvest time, respectively). Little is known about variation in fatty acid content or composition among Iranian fennel landraces. Therefore the objectives of the current study were to 1) evaluate potential oil production in Iranian fennel landraces, 2) evaluate their oil compositions, 3) identify high potential landraces.

\section{Material and methods}

Seeds of 50 fennel (Foeniculum vulgare var. vulgare) landraces provided by the seed bank of College of Aburaihan, University of Tehran (Bahmani et al., 2016, 2015, 2013, and 2012), were planted in a field under a randomized complete block design with three replications in an experimental field of College of Aburaihan. Each landrace was sowed in a $1 \mathrm{~m}^{2}$ plot in sandy-clay soil. Manual elimination of weeds and regular irrigation in $50 \%$ field capacity were performed. During the growing season, no diseases or pests were observed. After seedling emergence, seedlings were thinned to a final plant density of 10 plants per $\mathrm{m}^{2}$ for each landrace in each plot (Khorshidi et al., 2010; Falzari et al., 2006; El-Gengaihi and Abdallah, 1978). Wheat was grown in this field the two years before the current study; the wheat residues were incorporated in the soil, and no supplemental fertilizer was applied.

After the second year of growth in the field, seeds were harvested for the 50 landraces and fatty acids content was determined. Fatty acids were extracted from the seeds by hexane in an accelerated solvent extraction system (ASE) (Richter et al., 1996) at the University of Tehran (Figure 1). For this, seeds were milled and kept overnight in the oven at $105^{\circ} \mathrm{C}$ to reduce moisture content below $10 \%$, and then about $1.3 \mathrm{~g}$ of the dried milled seeds from each landrace was placed in an extraction cell. During the extraction process, the conditions were set to $105^{\circ} \mathrm{C}$ oven temperature, $10 \mathrm{~min}$ static time, $70 \%$ flush volume, $60 \mathrm{~s}$ purge time, two static cycles, and 6.89 $\mathrm{MPa}$ pressure. Afterward, the extracted oils were air-dried overnight, and then dry mass and oil percentage were calculated.

To identify oil compositions among Iranian fennels, twelve of the landraces were selected to represent different maturity habits and diverse regions of origin. The selection criteria within each maturity type were for landraces of diverse geographic origin to include a wide range of climate diversity. For each of the twelve landraces, three equal amounts of seeds, harvested from the three replications in the second year of a field study described above, were mixed and a single sample of seeds for each landrace was formed. These twelve seed samples were brought to Michigan State University in 2015, and their total fixed oil contents were extracted using the same method described above (ASE) and, after calculating the percentage of oil, the dry oil samples using $1 \mathrm{ml}$ hexane were collected.

For methyl esterification of fatty acids, the collected oil samples were dried again by evaporating the hexane, 
and then $1 \mathrm{ml}$ methanol: $\mathrm{H}_{2} \mathrm{SO}_{4}$ (5:1 by volume) was added to each sample and mixed for a few minutes. The samples were kept overnight at room temperature. The following day, $1 \mathrm{ml}$ chloroform and $5 \mathrm{ml}$ deionized water were added to each sample, and the supernatant phase containing fatty acid methyl esters (FAMEs) was separated. These fatty acids methyl esters were identified and quantified using Thermo TRACE gas chromatography Ultra coupled with DSQII mass spectrometry (GC-MS). C19:0 methyl ester as internal standard, and four concentrations $(0.4$ to $400 \mathrm{ng} / \mathrm{ml}$ ) of a 37-components FAME standard mixture as external standard were used. For each sample, three technical replications were performed. The 37-component FAME mix standard had a C18:1-9cis isomer of C18:1, which is oleic acid.

In GC, a DB-23 column $(30 \mathrm{~m} \times 0.25 \mathrm{~mm}$ i.d. $\times 0.25 \mathrm{~mm}$ film thickness $)$ was used, syringe washes done by ethyl acetate and hexane, injection volume was $1 \mathrm{ml}$, inlet temperature $250{ }^{\circ} \mathrm{C}$, and helium flow rate of 1.3 $\mathrm{ml} / \mathrm{min}$. The MS system had an electron ionization source operated at $70 \mathrm{eV}$ and a single quadrupole mass analyzer and was operated with a 3 min solvent delay and an ion source temperature of $250{ }^{\circ} \mathrm{C}$. The raw GC-MS result was processed in the MassLynx program to obtain the final data. The protocol used for oil extraction and GC-MS analysis is described in detail by Alameldin et al. (2017).

Fixed oil contents and fatty acids concentrations were reported as a percentage (\%), which for fixed oil contents means ml fixed oil per $100 \mathrm{~g}$ dry ripened seeds (seed mass), and for fatty acids concentrations means $\mathrm{ml}$ fatty acid per $100 \mathrm{ml}$ total fixed oil. Analyses of variance were performed using SAS 9.0, based on a randomized complete block design for oil contents.

\section{Results}

The 50 fennel landraces varied considerably for total oil content (Table 1; Figure 2), ranging from 9.5 to $23 \%$ of dried ripened seed mass. The average oil content was $13.45 \pm 0.44 \%$ among early maturity landraces, $17 \pm 0.74 \%$ among medium maturities, and $16.7 \pm 1.08 \%$ among late maturities. The highest oil contents among early maturity types belonged to Hamedan, Arak, and Mahalat landraces with $19.55 \pm 1.15 \%, 18.5 \pm 0.86 \%$, and $17.5 \pm 0.26 \%$, respectively. Among medium maturities, the Marvdasht, Kohn, and Meshkin Shahr landraces had the highest oil contents with $23 \pm 1.7 \%, 20.5 \pm 0.58 \%$, and $19 \pm 0.27 \%$, respectively, and among the late maturity fennels, Sari had the highest oil content with $21 \pm 0.57 \%$.

Using seed yield data from one of our previously published works (Bahmani et al, 2015), and total oil content data in this study, oil yields $\left(\mathrm{ml} / \mathrm{m}^{2}\right)$ for the 50 landraces were estimated (Figure 3). Among late maturity fennels Sari landrace $\left(71.4 \mathrm{ml} / \mathrm{m}^{2}\right)$, among medium maturities Meshkin Shahr and Moqhan landraces (92.4, and $85.4 \mathrm{ml} / \mathrm{m}^{2}$, respectively), and among early maturities Fasa, Saqez, and Rafsanjan landraces (65.3, 49.8, and $44 \mathrm{ml} / \mathrm{m}^{2}$, respectively) were the highest oil-yielding landraces.

Oil percentages of the twelve seed samples brought to Michigan State University were similar to the results from 2012. Oil compositions of the twelve landraces were quantified by GC-MS (Table 2). Sixteen different fatty acids were identified, which constituted $99.5 \%$ of the total oil in the samples. Among these, the most abundant fatty acids were oleic acid (52-64\%), linoleic acid (26-39\%), palmitic acid (0.3-4.1\%), linolenic acid (0.6-3.6\%), stearic acid (1.3-2.4\%), and myristic acid (0.35-1.07\%), arachidic acid (0.12-0.83\%) and lauric acid (0.15-0.58\%). The highest amounts of oleic acid belonged to the Khash, Fozveh, and Arak landraces; and the highest amounts of linoleic acid to Meshkin Shahr and Sari landraces.

The mean percentage of unsaturated fatty acids among the twelve landraces was $91.55 \pm 0.54 \%$ of the total oil content (Table 2; including 59.43 $\pm 1.33 \%$ monounsaturated fatty acid, mostly oleic acid, and $32.12 \pm 1.37 \%$ polyunsaturated fatty acid, mostly linoleic acid), while the mean saturated fatty acids was $7.67 \pm 0.63 \%$, which mostly was composed of palmitic acid and stearic acid.

The twelve fennel landraces were grouped based on their fatty acid profiles (Figure 4; Table 3), which yielded two groups. Group 1 contained higher contents of oleic acid $(62.3 \pm 0.95 \%)$, stearic acid $(1.91 \pm 0.11 \%)$, arachidic acid $(0.47 \pm 0.070 \%)$, and palmitic acid $(3.24 \pm 0.16 \%)$ than group 2, while group 2 contained higher contents of linoleic acid $(34.95 \pm 1.23 \%)$, and linolenic acid $(2.13 \pm 0.38 \%)$. Landraces included in group 1 (oleic acid chemotype) originated from regions with a dry and warm climate (Eastern Zagros Mountains, 
and southern Alborz mountains), while the landraces in group 2 (linoleic acid chemotype) originated from regions with a humid and cool climate (the western Zagros Mountains, and northern Alborz mountains).

\section{Discussion}

Finding new oil crops is necessary to meet increasing market demands, and also to diversify our current oil crops. Results presented here indicate that bitter fennel, due to its potential to produce high amounts of oil with a high percentage of unsaturated fatty acids, is a good candidate as a new seed oil crop. The 50 Iranian fennel landraces exhibited considerable diversity for oil yield, with Sari, Haji Abad, Meshkin Shahr, Moqhan, Kohin, Alamot, Marvdasht, Fasa, Saqez, and Rafsanjan producing the highest oil yields.

The main oil compositions in the twelve studied fennels were oleic acid and linoleic acid, which is similar to previous studies on fennel (Rezaei Chiyaneh et al., 2020; Hayat et al., 2019; Sayed Ahmad et al., 2018; Agarwal et al., 2018; Rebey et al., 2016; Nguyen et al., 2015; Acimovic et al., 2015; Bogdanov et al., 2015; Barros et al., 2010; Vidrih, et al., 2009; Cosge et al., 2008; Singh et al., 2006; Gupta et al., 1995; Reiter et al., 1998). It is reported that oleic acid is also one of the major fatty acids in other Apiaceae members, such as dill, celery, cumin, coriander, and carrot (Gao et al., 2016; Uitterhaegen et al., 2016; Sowbhagya, 2014; Amin et al., 2010; Saleh et al., 2009). The oleic acid chemotypes originated from regions with a dry and warm climate and the high linoleic acid chemotypes from regions with a humid and cool climate. This pattern shows potential evolutionary adaption of biochemical pathways to the environmental condition experienced by ancestors for a long time. Changes in fatty acid profiles by factors related to climate have been observed in many plant species (Mustiga et al., 2019; Raziei et al., 2018). One reason for such a pattern could be the partially shared biosynthetic pathway for oleic acid and linoleic acid, which may be by environmental factors. These factors may shift the pathway more toward one of the components and reduce the other one's production (negative correlation between oleic and linoleic acids). A pattern like what we found here, can help breeders in high throughput preliminary screening programs.

It has been reported that temperature is positively associated with palmitic, arachidic, and stearic acid concentrations while increasing temperature negatively impacts linoleic and oleic acid concentrations (Mustiga et al., 2019). Also, Raziei et al (2018) reported that lower temperature can increase the production of unsaturated fatty acids, such as oleic and linoleic acids. Hixson and Arts (2016) reported that phytoplankton temperature is negatively associated with omega-3 fatty acids, such as linolenic acid, while positively is associated with omega- 6 fatty acids, such as linoleic. For the most part, our results are compatible with these previous studies, except about oleic acid, which was similar to what Hixson and Arts (2016) reported, but opposite of what Mustiga et al (2019) and Raziei et al (2018) reported. Definitely, analyzing a higher number of samples from different climates could clarify potential relationships between temperature and oleic acid production.

The fennel landraces comprising group 1, compared to those in group 2, had the higher amounts of monounsaturated fatty acids $(62.6 \pm 0.9 \%$ vs $55 \pm 1.2 \%)$ and also saturated fatty acids $(8.8 \% \pm 0.7$ vs $6.1 \% \pm 0.6)$, while those from group 2 had more polyunsaturated acids than those in group 1 ( $37.1 \% \pm 1.2$ vs $28.5 \% \pm 0.4)$. Compared to those in group 1, the landraces from group 2 originated from cool/wet climates, had a higher

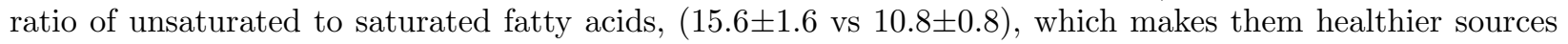
of oil for human use. Among the twelve fennels landraces profiled, Qazvin, Sari, Rafsanjan, Meshkin Shahr, and Chahestan landraces had the highest ratios of omega- 3 to omega- $6(0.11,0.06,0.06,0.05$, and 0.05 , respectively) fatty acids.

Taking all these points into consideration, the Meshkin Shahr landrace, with high ratios of unsaturated to saturated fatty acids (15.85), and omega-3 to omega-6 (0.05) has great potential among all the evaluated landraces as a potential source of edible oil. This landrace was also the highest oil yielding landrace. Therefore, we recommend it for further studies to be considered as a high yielding source of healthy edible oils.

\section{Reference}

Acimovic, M., Popovic, S., Kostadinovic, L., Stankovic, J., Cvetkovic, M. 2015. Characterization of fatty 
acids and essential oil from sweet and bitter fennel fruits growing in Serbia. Sixth international scientific agricultural symposium, Agrosym

Agarwal, D., Saxena, S. N., Sharma, L. K., Lal, G. 2018. Prevalence of essential and fatty oil constituents in fennel (Foeniculum vulgare mill) genotypes grown in semi-arid regions of India. Journal of Essential Oil Bearing Plants. 21(1): 40-51

Alameldin, H., Izadi Darbandi, A., Smith, S. A., Balan, V., Jones, D., Sticklen, M. 2017. Production of SeedLike Storage Lipids and Increase in Oil Bodies in Corn (Maize; Zea mays L.) Vegetative Biomass. Industrial Crops and Products. 108: 526-534

Amin, S., Mir, ., Kohli, K., Ali, B., Ali, M. 2010. A study of the chemical composition of black cumin oil and its effect on penetration enhancement from transdermal formulations. Natural Product Researches. 24(12): $1151-1157$

Bahmani, K., Izadi Darbandi, A., Jafari, A. A., Sadat Noori, S. A., Farajpour, M. 2012. Assessment of genetic diversity in Iranian fennels using ISSR markers. Journal of Agricultural Science. 4(9): 79-84

Bahmani, K., Izadi Darbandi, A., Sadat Noori, S. A., Jafari, A. A. 2013. Assessment of the genetic diversity in Iranian fennels by RAPD markers. Journal of Herbs, Spices and Medicinal Plants. 19: 275-285

Bahmani, K., Izadi Darbandi, A., Ramshini, H. A., Moradi, N., Akbari, A. 2015. Agro-morphological and phytochemical diversity of various Iranianfennel landraces. Industrial Crops and Products. 77: 282-294

Bahmani, K., Izadi Darbandi, A., Faleh Alfekaiki, D., Sticklen, M. 2016. Phytochemical diversity of fennel landraces from various growth types and origins. Agronomy Research. 14(5): 1530-1547

Barros, L., Carvalho, A. M., Ferreira, I. C. F. R. 2010. The nutritional composition of fennel (Foeniculum vulgare): Shoots, leaves, stems and inflorescences. Food Science and Technology. 43: 814-818

Bogdanov, M. N., Bogdanov, J. B., Stefova, M. 2015. Simultaneous Determination of Essential Oil Components and Fatty Acids in Fennel using Gas Chromatography with a Polar Capillary Column. Natural Product Communications. 10(9): 1619-1626

Cosge, B., Kiralan, B. and Gurbuz, B. 2008. Characteristics of fatty acids and essential oil from sweet fennel (F. vulgare Mill. var. dulce) and bitter fennel fruits (F. vulgare Mill. var. vulgare). Natural Product Research. 22 (12): 1011-1016

El-Gengaihi, S., Abdallah, N. 1978. The effect of date of sowing and plant spacing on yield of seed and volatile oil of fennel (Foeniculum vulgare Mill.). Pharmazie. 33(9): 605-606

Falzari, L. M., Menary, R. C., Dragar, V. A. 2006. Optimum stand density for maximum essential oil yield in commercial fennel crops. Hortscience. 41(3): 646-650

Gao, F., Yang, S., Birch. J. 2016. Physicochemical characteristics, fatty acid positional distribution and triglyceride composition in oil extracted from carrot seeds using supercritical CO2. Journal of Food Composition and Analysis. 45: 26-33

Gupta, K., Thakral, K. K., Gupta, V. K., Arora, S. K. 1995. Metabolic Changes of Biochemical Constituents in Developing Fennel Seeds (Foeniculum vulgare). Journal of the Science of Food and Agriculture. 68: 73-76

Hayat, K., Abbas, S., Hussain, S., Shahzad, S. A., Tahir, M. U. 2019. Effect of microwave and conventional oven heating on phenolic constituents, fatty acids, minerals and antioxidant potential of fennel seed. Industrial Crops and Products. 140: 1-8

He, W., Huang, B. 2011. A review of chemistry and bioactivities of a medicinal spice: Foeniculum vulgare. J Med Plant Res. 5: 3595-3600

Hixson, S. M., Arts, M. T. 2016. Climate warming is predicted to reduce omega-3, long-chain, polyunsaturated fatty acid production in phytoplankton. Global Change Biology. 22(8): 2744-2755 
Hornok, L. 1992. The cultivating and Processing of Medicinal Plants. John Wiley, New York. pp 338

Khorshidi, J., Fazel Mirahmadi, S., Fakhr Tabatabaei, M. 2010. Oil content and yield of Foeniculum vulgare Mill. cv. Soroksary seeds as affected by different plant cultivation densities. Journal of American Science. 6(11): $1098-1100$

Lietava, J. 1992. Medicinal plants in a middle paleolithic grave Shanidar IV. J. Ethnopharmacology. 35(2): 263-266

Matthaus, B., Ozcan, M. M. 2015. Oil content, fatty acid composition and distributions of vitamin-E-active compounds of some fruit seed oils. Antioxidants. 4: 124-133

Mustiga, G. M., Morrissey, J., Stack, J. C., DuVal, A., Royaert, S., Jansen, J., Bizzotto, C., Villela-Dias, C., Mei, L., Cahoon, E. B., Seguine, E., Marelli, J. P., Motamayor, J. C. 2019. Identification of Climate and Genetic Factors That Control Fat Content and Fatty Acid Composition of Theobroma cacao L. Beans. Frontiers in Plant Science. 10: 1-20

Nguyen, T., Aparicio, M., Saleh, M. A. 2015. Accurate Mass GC/LC-Quadrupole Time of Flight Mass Spectrometry Analysis of Fatty Acids and Triacylglycerols of Spicy Fruits from the Apiaceae Family. Molecules. 20: $21421-21432$

Rebey, I. B., Saidani Tounsi, F. Z. R., Marzouk, M. B., Ksouri, R. 2016. Variation in fatty acid and essential oil composition of sweet fennel (Foeniculum vulgare Mill) seeds as affected by salinity. Journal of new sciences, Agriculture and Biotechnology. 6: 1233-1240

Reiter, B., Lechner, M., Lorbeer, E. 1998. The fatty acid profiles - including oleic and cis-vaccenic acid - of different Umbelliferae seed oils. Fett/Lipid. 100(11): 498-502

Raziei, Z., Kahrizi, D., Rostami-Ahmadvandi, H. 2018. Effects of climate on fatty acid profile in Camelina sativa. Cellular and Molecular Biology. 64(5): 91-96

Rezaei Chiyaneh, E., Amirnia, R., Amani Machiani, M., Javanmard, A., Maggi, F., Morshedloo, M. R. 2020. Intercropping fennel (Foeniculum vulgare L.) with common bean (Phaseolus vulgaris L.) as affected by PGPR inoculation: A strategy for improving yield, essential oil and fatty acid composition. Scientia Horticulturae. 261

Richter, B. E., Jones, B. A., Ezzell, J. L., Porter, N. L. 1996. Accelerated Solvent Extraction: A Technique for Sample Preparation. Analytical Chemistry. 68: 033-1039

Saleh, M., Kumar Roy, S., Islam, R. 2009. Fatty acid composition of dill (Anethum sowa) flower. Jahangirnagar University Journal of Science. 32(2): 1-8

Sales Campos, H., Souza, P. R., Peghini, B. C., Da Silva, J. S., Cardoso, C. R. 2013. An overview of the modulatory effects of oleic acid in health and disease. Mini Review in Medicinal Chemistry. 13(2): 201-210

Sayed Ahmad, B., Talou, T., Saad, Z., Hijazi, A., Cerny, M., Kanaan, H., Chokr, A., Merah, O. 2018. Fennel oil and by-products seed characterization and their potential applications. Fennel oil and by-products seed characterization and their potential applications. Industrial Crops and Products. 111: 92-98

Simopoulos, A. P. 2008. The importance of the omega-6/omega-3 fatty acid ratio in cardiovascular disease and other chronic diseases. Experimental Biology and Medicine. 233(6): 674-688

Singh, G., Maurya, S., Lampasona, P., Catalan, C. 2006. Chemical constituents antifungal and antioxidative potential of Foeniculum vulgare volatile oil and its acetone extract. Food Control. 17: 745-752

Singh, G., Maurya, S., Lampasona, M. P., Catalan, C. 2006. Chemical constituents, antifungal and antioxidative potential of Foeniculum vulgare volatile oil and its acetone extract. Food Control. 17: 745-752

Singh, V. V., Divakara Sastry, E. V. 2006. Genetic variance and expected selection response in fennel (Foeniculum vulgare Miller). Indian Journal of Genetics. 66(1): 63-64 
Sowbhagya, H. B. 2014. Chemistry, technology, and nutraceutical functions of celery (Apium graveolens L.): an overview. Critical Reviews in Food Science and Nutrition. 54(3): 389-98

Uitterhaegen, E., Sampaio, K. A., Delbeke, E. I. P., Greyt, W. D., Cerny, M., Evon, P., Merah, O., Talou, T., Stevens, C. V. 2016. Characterization of French coriander oil as source of petroselinic acid. Molecules. 21(9): 1-13

Vidrih, R., Filip, S., Hribar, J. 2009. Content of higher fatty acids in green vegetables. Czech Journal of Food Sciences. 27: 125-129

\section{Hosted file}

Tables.pdf available at https://authorea.com/users/398380/articles/511014-variation-infatty-acid-content-and-composition-among-iranian-fennel-landraces

\section{Hosted file}

Figures.pdf available at https://authorea.com/users/398380/articles/511014-variation-infatty-acid-content-and-composition-among-iranian-fennel-landraces 